\title{
THE INFLUENCE OF WATER AND MINERAL OIL ON VOLUMETRIC LOSSES IN A HYDRAULIC MOTOR
}

\author{
Pawel Śliwiński \\ Gdansk University of Technology, Faculty of Mechanical Engineering, Poland
}

\begin{abstract}
In this paper volumetric losses in hydraulic motor supplied with water and mineral oil (two liquids having significantly different viscosity and lubricating properties) are described and compared. The experimental tests were conducted using an innovative hydraulic satellite motor, that is dedicated to work with different liquids, including water. The sources of leaks in this motor are also characterized and described. On this basis, a mathematical model of volumetric losses and model of effective rotational speed have been developed and presented. The results of calculation of volumetric losses according to the model are compared with the results of experiment. It was found that the difference is not more than 20\%. Furthermore, it has been demonstrated that this model well describes in both the volumetric losses in the motor supplied with water and oil. Experimental studies have shown that the volumetric losses in the motor supplied with water are even three times greater than the volumetric losses in the motor supplied with oil. It has been shown, that in a small constant stream of water the speed of the motor is reduced even by half in comparison of speed of motor supplied with the same stream of oil.
\end{abstract}

Keywords: volumetric losses, satellite motor, water, oil

\section{INTRODUCTION}

Hydraulic motor in the hydraulic system is the executive element. Its purpose is to convert hydraulic energy into mechanical one. An energy carrier in the hydraulic systems is liquid. The type of liquid is conditioned by the requirements for these systems. In most hydraulic systems mineral oil is commonly used $[3,4,5,6,24]$. However, in some industrial sectors, the requirement is a non-flammable liquid (mining, steel mills, etc.) or non-toxicity for the environment and human health (food industry) [13]. The liquid which is nonflammable and non-toxic and certainly suitable for energy transfer in hydraulic systems is water.

There is a growing trend in the world towards research and development of components and hydraulic systems supplied with water $[3,7,13,23]$.

Such studies are also of particular importance in marine technology, where hydraulic power circuits are used a lot, and the water is a generally available working liquid [2]. In comparison to mineral oil water has a very low viscosity and low lubricating properties [8]. These features adversely influence the efficiency of energy conversion in hydraulic systems [21,22]. Despite this, attempts are made to develop innovative components and hydraulic systems supplied with water $[13,14]$.

So far, each hydraulic device is dedicated to a specific type of working liquid. For example, a hydraulic motor dedicated for oil systems should not be used in systems where the working medium is water. In other case this motor has low efficiency and very little durability [22].

Both the pump and the hydraulic motor are components of the hydraulic system, in which there are large energy losses $[1,9,10,11,21,22,24]$. The biggest influence on the volumetric losses in hydraulic displacement machines has a leakage in the clearances of working mechanism $[1,9,11,12,14,17,19,20,21,22$, 24]. It has been proved that in a motor working mechanism clearances that a not-fully developed turbulent flow takes place. This is particularly well visible in the case of supplying a hydraulic motor with low viscosity liquid $[14,16,20]$. Besides, 
in the hydraulic motor, there are other sources of volumetric losses, in addition to the clearances. The sources of these losses are described later in this article.

Considering water as a working fluid one should expect particularly high volumetric losses in machines, greater than the ones with mineral oil. So far there is a lack of results of research comparing the influence of water and mineral oil on volumetric losses in pumps and hydraulic motors. There is also no specific information about the design of pumps and motors, which can be supplied with both water and mineral oil. There is rich literature on flows in different flat gaps, orifices and other simple openings. Furthermore, there is no rich studies in literature that compare the influence of type of liquid on flow characteristics in these gaps. In literature the volumetric losses have been describe in general without specifying the type of clearances $[1,9,11,20,21]$. In addition, the leakage of low viscosity liquid is described by a different model than the leakage of high viscosity liquids (mineral oil, rapeseed oil) [20,21].

Therefore, from the scientific and cognitive point of view, the research and description of water and mineral oil influence on volumetric losses in a hydraulic motor is appropriate and justified. The development of a universal mathematical model describing the volumetric losses in the motor supplied either by liquid of high viscosity or low viscosity is also appropriate and reasonable. Therefore, the issue of the influence of the type of liquid on the volumetric losses in the hydraulic motor is a new issue and represents an important scientific problem. Consequently, the following objectives were stated in this article:

a) indication and description of sources of volumetric losses in the motor;

b) description of the mathematical model of the volumetric losses;

c) comparison of volumetric losses in motor supplied with mineral oil and water;

d) comparison of results of experimental research with mathematical model.

The experimental research of the influence of the type of liquid on volumetric losses was carried out on a prototype of a hydraulic satellite motor, developed by the author.

\section{SATELLITE MOTOR}

For experimental tests a prototype of satellite motor was selected marked with the symbol SM-0,75/25. The design of this motor is presented in Fig. 1. The working mechanism of the satellite motor is a specific gear mechanism in which the rotor revolves around the shaft axis and the revolving motion is done by satellites which are in gear with the stator and the rotor (Fig. 2).

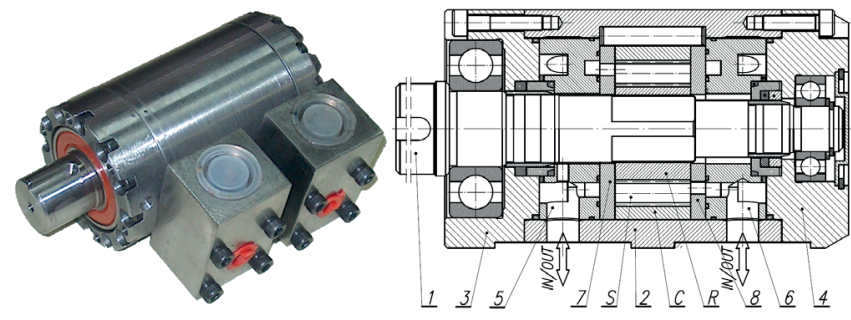

Fig. 1. General view and axial cross section of satellite motor (SM type): $C$ - stator, $S$ - satellite, $R$ - rotor, 1 - shaft, 2 - casing, 3 - front casing, 4 - rear casing, 5 and 6 - inlet and exit manifold, 7 and 8 - compensation (commutation) plates $[14,16,17]$

The toothed unit, shown in Fig. 2, is the satellite working mechanism of the motor. It consists of a toothed rotor $\mathrm{R}$ (4 humps), toothed stator C (6 humps) and ten $\mathrm{S}$ wheels (satellite).

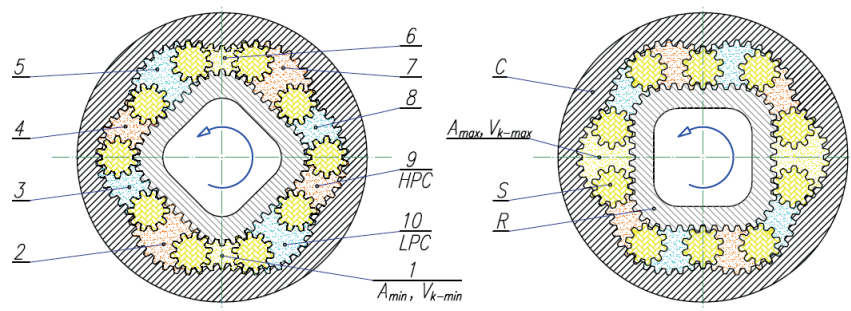

Fig. 2. The working mechanism of a satellite motor: $C$ - stator, $R$-rotor, $S$ - satellite, $1 \div 10$ - working chambers, LPC - low pressure working chamber, HPC - high pressure working chamber, $V_{k \text {-min }}$ - working chamber with minimum area $A_{\text {min }}$ (dead chamber), $V_{k \text { max }}-$ working chamber with maximum area $A_{\max }[12,14,16,17,18,20]$

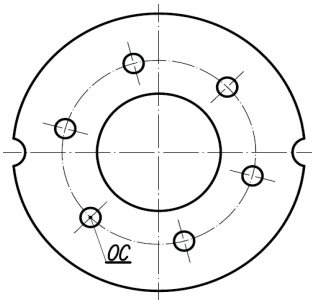

Fig. 3. Distribution plate: OC - inflow/outflow hole [12,14,16,17,18,20]

The stator is toothed inside and consists of six humps. The rotor is toothed outside and consists of four humps. Gear wheels called satellites work with the stator and the rotor. Spaces, called working chambers, are formed between the satellites, the stator and the rotor. The number of working chambers is equal to the number of satellites.

During the rotor rotation the working chambers:

a) change their volume from minimum $V_{k-m i n}$ to maximum $\mathrm{V}_{\mathrm{k}-\max }$ forming a high pressure chamber HPC. The chamber is filled with water;

b) change their volume from maximum $V_{k-\max }$ to minimum $\mathrm{V}_{\mathrm{k}-\min }$ forming a low pressure chamber LPC. The chamber is emptied of liquid.

The working chambers in the satellite mechanism are closed by the compensation plates (Fig. 1 - elements 7 and 8, and Fig. 3), which also play the role of distribution plates. 
The number of filling and emptying cycles of the working chambers per one rotation of the shaft is the product of the number of humps of the rotor and the stator. Thus, 24 cycles correspond to one shaft revolution.

The results of research, described in the following section concern the satellite motor type SM-0,75/25 with the following parameters:

- theoretical displacement $\mathrm{q}_{\mathrm{t}}=32,94 \mathrm{~cm}^{3} / \mathrm{rev}$;

- teeth module $\mathrm{m}=0,75 \mathrm{~mm}$;

- height of working mechanism $\mathrm{H}=25 \mathrm{~mm}$;

- axial clearance of satellites $h_{\mathrm{s}}=5,35 \mathrm{um}$;

- axial clearance of rotor $h_{R}=6,38 u m$.

\section{SOURCES OF VOLUMETRIC LOSSES}

In the positive displacement machines the sources of volumetric losses are:

a) the liquid flow rate in flat clearances in satellite mechanism (Fig. 4);

b) the liquid flow rate in clearances in commutation unit (short clearances) in satellite mechanism (Fig. 5);

c) the liquid flow rate in the spaces between the teeth of the working mechanism (tip clearances Tc and backlashes $\mathrm{G}$ ) (Fig. 6);

d) the liquid flow rate caused by the cyclic elastic deformation of the working chambers, mainly due to the cyclic deformation of the stator as the element with the smallest stiffness;

e) the liquid flow rate depending on its compressibility.

In all satellite motors the internal leakage is discharged into the low-pressure channel (outflow channel).

\section{FLOW RATE $Q_{\text {LFG }}$ IN FLAT CLEARANCES OF WORKING MECHANISM}

Flow rate $\mathrm{Q}_{\mathrm{Lfg}}$ in flat clearances (Fig. 4) of working mechanism are described by equation $[14,17]$ :

$$
Q_{L f g}=A_{1} \cdot m^{\left(\frac{1-\beta}{2-\beta}\right)} \cdot\left(\frac{1}{v}\right)^{\left(\frac{\beta}{2-\beta}\right)} \cdot\left(\frac{2 \cdot h^{3}}{K \cdot A_{2} \cdot \rho}\right)^{\left(\frac{1}{2-\beta}\right)} \cdot \Delta p_{i}^{\left(\frac{1}{2-\beta}\right)}
$$

where:

- $\beta$ - the degree of laminarity of the flow [17];

$-v$ - kinematic viscosity of liquid;

- $\rho$ - density of liquid;

- $\mathrm{m}$ - teeth module;

- $A_{1}, A_{2}, K$ - coefficients;

- $\mathrm{h}$ - equivalent axial clearances of rotor and satellites, described as $[14,17]$ :

$$
h=\frac{h_{R}+h_{S}}{2}-\left(D_{C} \cdot H+D_{k}\right) \cdot \Delta p_{i}
$$

- $h_{R}$ and $h_{S}$ - respectively: axial clearance of rotor and satellites;

- $\mathrm{H}$ - height of working mechanism (equal to height of curvature);
- $\mathrm{D}_{\mathrm{k}}$ - the coefficient depends on stiffness of axial clearance compensation unit;

- $\mathrm{D}_{\mathrm{C}}$ - the coefficient depends on stiffness of stator.

The formula (1) is true if (Fig. 4):

$$
Q_{L f g-1}+Q_{L f g-2}=Q_{L f g}
$$

and

$$
\Delta p_{i-1} \approx \Delta p_{i-1} \approx \Delta p_{i}
$$

The values of $\beta, A_{1}, A_{2}, K, D_{k}$ and $D_{C}$ are given in Table 1 .

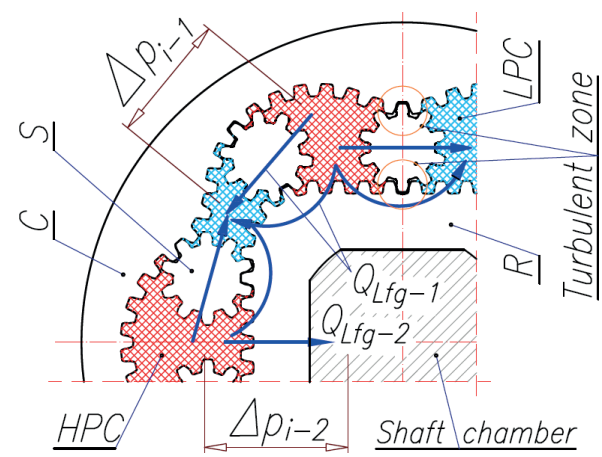

Fig. 4. The flows in flat clearances [17]

\section{FLOW RATE $Q_{C}$ IN COMMUTATION UNIT CLEARANCES (SHORT CLEARANCE)}

Fig. 5 presents the process of passage of the low-pressure working chamber LPC through the dead chamber $\mathrm{V}_{\mathrm{k}-\mathrm{min}}$ into the high-pressure working chamber HPC. Two commutation unit clearances are formed during this process. There is leakage in these clearances which results from the pressure difference in the $\mathrm{IH}$ and $\mathrm{OH}$ channels:

a) $\mathrm{Q}_{\mathrm{Cm} 1}$ - from channel IH to chamber $\mathrm{V}_{\mathrm{k}-\mathrm{min}}$, caused by the pressure difference $\Delta \mathrm{p}_{1}$;

b) $\mathrm{Q}_{\mathrm{Cm} 2}$ - from chamber $\mathrm{V}_{\mathrm{k}-\mathrm{min}}$ to channel $\mathrm{OH}$, caused by the pressure difference $\Delta \mathrm{p}_{2}$

A similar process occurs during the transition of chamber HPC to LPC.

The leakage occurs in the range of a very small shaft rotation angle $\alpha=\left(-a_{b} ;+a_{b}\right)$. For further considerations, it is assumed that:

a) the angular shaft position $\alpha=0^{\circ}$ corresponds to chamber $\mathrm{V}_{\mathrm{k} \text {-min }}$ or chamber $\mathrm{V}_{\mathrm{k} \text {-max }}$;

b) angle $a_{b}$ is the critical value of angle $\alpha$, for which $Q_{C m 1}=$ $\mathrm{Q}_{\mathrm{Cm} 2}=0$. 

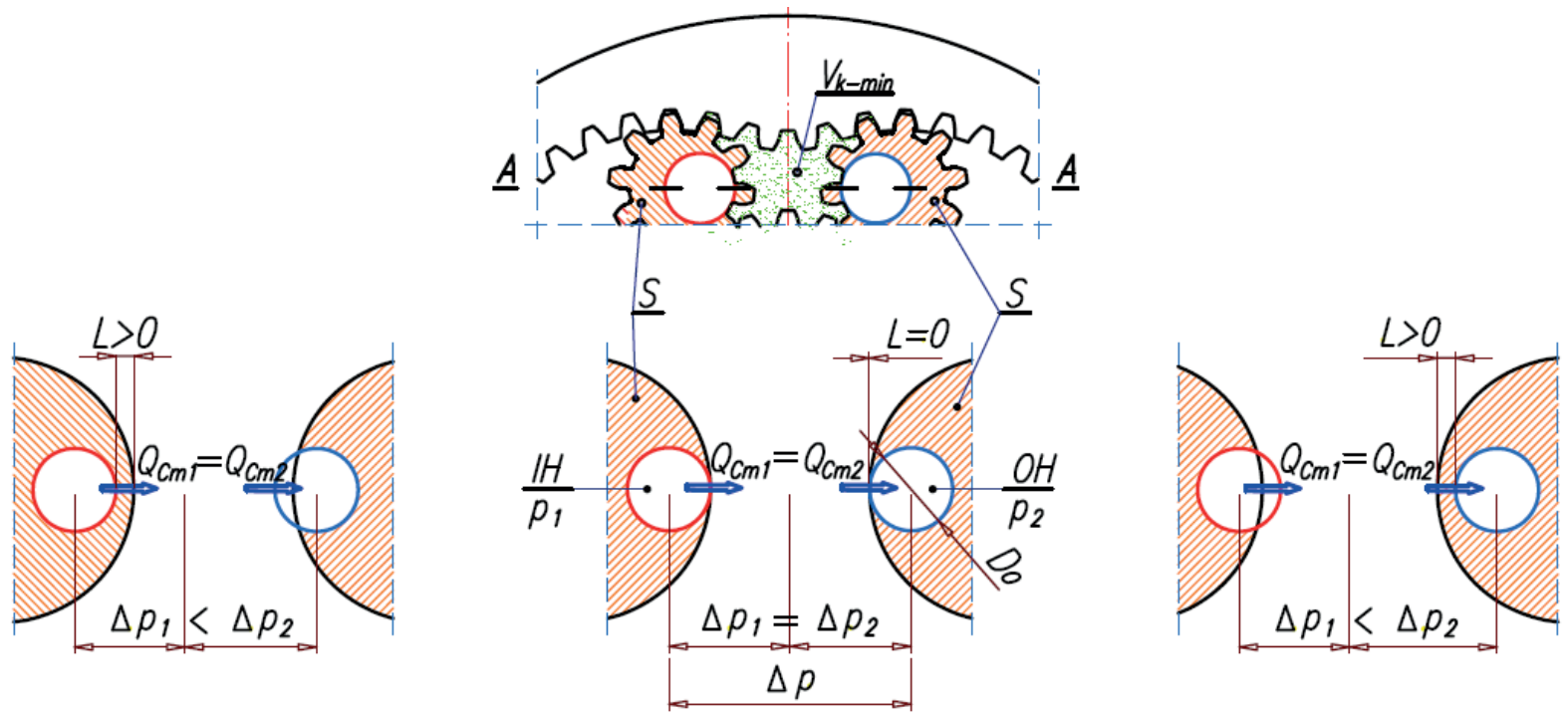



a) $\alpha=\left(-\alpha_{b}, 0\right)$

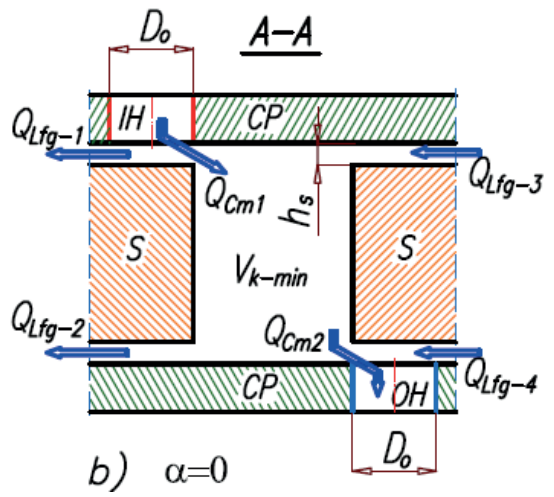

Assuming that:

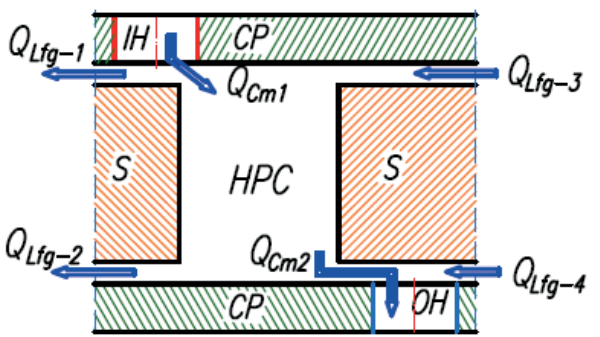

c) $\alpha=\left(0, \alpha_{b}\right)$
Fig. 5. Process of transition of chamber LPC to HPC via $V_{k-\min }[14,15]$ : a) final phase of reducing the LPC chamber volume $\left.\left(\alpha=\left(-\alpha_{k}, 0\right)\right) ; b\right)$ chamber $V_{k}$

$(\alpha=0)$; c) initial phase of increasing the HPC chamber volume $\left(\alpha=\left(0, \alpha_{b}\right)\right)$

The flow rate in commutation unit clearances is described by equation $[14,15]$ :

$$
Q_{C}=C_{1} \cdot\left(D_{o} \cdot h_{s}\right)^{C_{2}} \cdot\left(\frac{1}{\rho \cdot v^{C_{3}}}\right)^{\gamma} \cdot \Delta p_{i}^{\gamma}
$$

The value of coefficients $\mathrm{C}_{1}, \mathrm{C}_{2}, \mathrm{C}_{3} \mathrm{i} \gamma$ for motor SM-0,75/25 are given in Table 1 .

\section{FLOW RATE DQ $\mathrm{FC}_{\mathrm{FC}}$ DEPENDS ON COMPRESSIBILITY OF LIQUID}

The compressibility of liquid $\beta_{1}$ is defined as:

$$
\beta_{l}=\frac{\Delta V}{V} \cdot \frac{1}{\Delta p}
$$

where:

- V, $\Delta \mathrm{V}$ - respectively: volume, change of the volume of the liquid;

- $\Delta \mathrm{p}$ - pressure increase.

$$
\Delta Q_{f c}=\frac{\Delta V}{\Delta t}
$$

and

$$
Q_{t}=\frac{V}{=} q_{t} \cdot n
$$

and transforming the formula (25) one obtains:

$$
\Delta Q_{f c}=C_{f c}{ }^{\prime} \cdot \beta_{l} \cdot q_{t} \cdot n \cdot \Delta p_{i}
$$

where:

- $\Delta \mathrm{t}$ - an increment time;

- $\mathrm{n}$ - rotational speed;

- $\mathrm{C}_{\mathrm{fc}}{ }^{\prime}$ - the coefficient.

The theoretical displacement $\mathrm{q}_{\mathrm{t}}$ depends on teeth module $\mathrm{m}$ and high $\mathrm{H}$ of satellite working mechanism. For the mechanism as shown in Fig. $2 \mathrm{q}_{\mathrm{t}}$ can be expressed by the formula [14]:

$$
q_{t}=\left(A_{\max }-A_{\min }\right) \cdot H=87,53 \cdot m^{2} \cdot H
$$

where (Fig. 2):

- $\mathrm{A}_{\max }$ - maximum area of working chamber;

- $A_{\text {min }}-$ minimum area of working chamber. 
Thus:

$$
\Delta Q_{f c}=\underbrace{87,53 \cdot C_{f c}{ }^{\prime}}_{C_{f c}} \cdot \beta_{l} \cdot m^{2} \cdot H \cdot \Delta p_{i} \cdot n
$$

If in the commutation unit is zero overlap or positive overlap, then there is a compression of fluid in the death volumes. Furthermore, a compression of the liquid in the spaces between the teeth can occur. These phenomena have no effect on the volumetric losses. The increase of pressure in the working chamber starts from the supply pressure $\mathrm{p}_{\mathrm{i}-1}$ in the working chamber increasing in volume to a pressure $\mathrm{p}_{\mathrm{i} \text {-max }}$ in the maximum volume $\mathrm{V}_{\mathrm{k} \text {-max }}$. Then, the pressure decreases to a value of $\mathrm{p}_{\mathrm{i}-2}$ in the working chamber reducing its volume. The value of pressure $\mathrm{p}_{\mathrm{i} \text {-max }}$ depends on the axial clearances of the satellites and the rotor and depends on the rotational speed. At low speeds, the pressure $\mathrm{p}_{\mathrm{i} \text {-max }}$ does not reach large values. It is estimated that as a result of the flow of liquid from the maximum volume $\mathrm{V}_{\mathrm{k}-\max }$, through clearances, to the low pressure chamber, the $\mathrm{p}_{\mathrm{i} \text {-max }}$ is close to the $\mathrm{p}_{\mathrm{i}-1}$. And at high rotational speeds the liquid does not have time to flow through the clearances to the low pressure chamber. As a result, depending on the type of liquid and its compressibility, the pressure $\mathrm{p}_{\mathrm{i}-\max }$ is considerably higher than the pressure $\mathrm{p}_{\mathrm{i}-1}$. Then the value of $\mathrm{p}_{\mathrm{i}-\max }$ has an effect only on the torque of mechanical losses in the motor.

In death volume $\mathrm{V}_{\mathrm{k}-\mathrm{min}}$, there is a minimum pressure $\mathrm{p}_{\mathrm{i} \text {-min }}$ similar to the $\mathrm{p}_{\mathrm{i}-2}$.

\section{FLOW RATE $\Delta Q_{\text {DCH }}$ CAUSED BY THE ELASTIC DEFORMATION OF THE WORKING CHAMBERS}

Elastic deformation of the working chambers in satellite mechanism is caused by the pressure difference $D p_{i}$ in these chambers and the change in pressure in the volumes $\mathrm{V}_{\mathrm{k} \text {-min }}$ and $\mathrm{V}_{\mathrm{k}-\mathrm{max}}$. As a result, the displacement of the motor is changing about $\mathrm{Dq}_{\mathrm{dch}}$. The flow rate $D Q_{\mathrm{dch}}$ is proposed to be express with a simplified equation [14]:

$$
\Delta Q_{d c h}=\Delta q_{d c h} \cdot n=\underbrace{87,53 \cdot \frac{C_{d c h}{ }^{\prime}}{K_{c h}}}_{C_{d c h}} \cdot m^{2} \cdot H \cdot \Delta p_{i} \cdot n
$$

where:

- $\mathrm{C}_{\mathrm{dch}}$ - the coefficient;

- $\mathrm{K}_{\mathrm{ch}}$ - the stiffness of working mechanism.

\section{FLOW RATE $D_{\mathrm{B}}$ DEPENDS ON TIP CLEARANCE AND BACKLASH}

The spaces between the teeth in satellite mechanism (tip clearance and backlash - Fig. 6) is the cause of volumetric losses $D Q_{b}$. The value of $D Q_{b}$ is proportional to the motor speed $n$. The increase of $D p_{i}$ causes an increase in elastic deformation of:

- the teeth, that is the spaces between the teeth increase;

- the rotor and stator, that is the backlash increase.

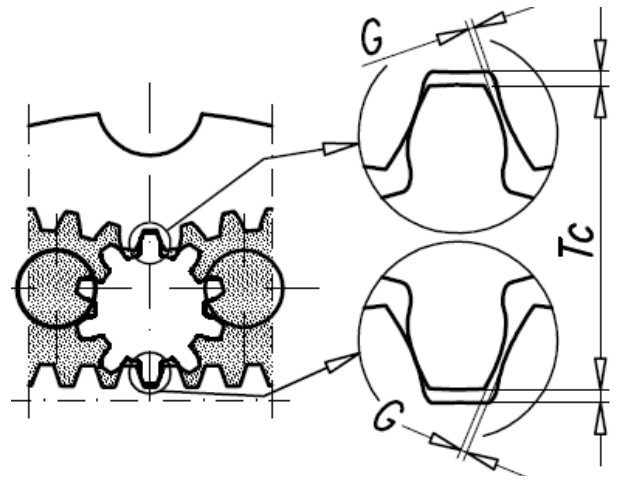

Fig. 6. Tip clearance Tc and backlash G [19]

Thus, the flow rate $D Q_{b}$ is proposed to be express with the simplified formula [14]:

$$
\Delta Q_{b}=\Delta q_{b} \cdot n=C_{b} \cdot m^{2} \cdot H \cdot \Delta p_{i} \cdot n
$$

where:

- $\Delta q_{b}$ - the change of displacement caused by the movement of satellites in spaces between the teeth;

- $\mathrm{C}_{\mathrm{b}}$ - the coefficient.

\section{FLOW RATE DQ ${ }_{\text {ID }}$ DEPENDS ON THE INERTIA OF THE SATELLITES AND THE LIQUID IN WORKING CHAMBERS AND DEPENDS ON THE DAMPING PROPERTIES OF LIQUID}

If increasing the rotational speed of the operating mechanism increases, then the acceleration of satellites increases and the acceleration of the liquid in the chambers increases also. As a result, the inertia forces of the liquid and satellites increase. At the time of change the commutation unit phase (e.g. at the time of opening the inflow and cut-off the outflow from the working chamber) these forces are opposed to changing the position of satellites in the space between the rotor teeth and in the space between the stator teeth. In addition, the speed of the "jump" teeth of satellites, when changing commutation unit phase, depends on the damping properties of the working liquid (that is: the viscosity, the density and compressibility of the liquid). The impact of above factors on the volumetric losses $D Q_{i d}$ is proposed to be describe with the simplified formula [14]:

$$
\Delta Q_{i d}=C_{i d} \cdot m^{2} \cdot H \cdot n^{0,5}
$$

where $\mathrm{C}_{\mathrm{id}}$ is the coefficient.

\section{EXTERNAL LEAKAGE $Q_{\text {EX }}$}

External leakage $\mathrm{Q}_{\mathrm{ex}}$ in the hydraulic motor is unacceptable, that is $\mathrm{Q}_{\mathrm{ex}}=0$. 


\section{MATHEMATICAL MODEL OF VOLUMETRIC LOSSES}

\section{KNOWN MODEL OF VOLUMETRIC LOSSES}

The literature describes the volumetric losses $\mathrm{Q}_{\mathrm{vl}}$ as follows: a) in motor supplied with oil $[1,21]$ :

$$
Q_{v l, O}=\Delta Q_{v l, O}+Q_{l, O}+Q_{t, O}+Q_{e x, O}
$$

b) in motor supplied with low viscosity liquid (like water or HFA-E emulsion) [20,21]:

$$
Q_{v l, E}=\underbrace{k_{c} \cdot \Delta Q_{v l, O}}_{\Delta Q_{v l, E}}+\underbrace{k_{s} \cdot\left(Q_{l, O}+Q_{t, O}\right)}_{Q_{l-t, E}}+\underbrace{k_{e x} \cdot Q_{e x, O}}_{Q_{e x, E}}
$$

In the above formulas $[1,20,21]$ :

$\Delta \mathrm{Q}_{\mathrm{vl}} \mathrm{O}, \Delta \mathrm{Q}_{\mathrm{vl}} \mathrm{E}$ - the component of volumetric losses depends on drop pressure $\Delta \mathrm{p}_{\mathrm{i}, \mathrm{O}}$ in motor working chamber and depends on angular velocity $\omega$ of motor shaft. In a motor supplied with oil this component is expressed by the formula:

$$
\Delta Q_{v l, O}=C_{v l, O} \cdot \frac{q_{t}}{2 \cdot \pi} \cdot \Delta p_{i, O} \cdot \omega
$$

and in a motor supplied with emulsion:

$$
\Delta Q_{v l, O}=\underbrace{k_{c} \cdot \mathrm{C}_{v l, O}}_{\mathrm{C}_{v l, \mathrm{E}}} \cdot \frac{q_{\mathrm{t}}}{2 \cdot \pi} \cdot \Delta \mathrm{p}_{\mathrm{i}, \mathrm{E}} \cdot \omega
$$

- $\Delta \mathrm{p}_{\mathrm{i}, \mathrm{O}}$ - drop pressure in working chamber of motor supplied with oil;

- $\Delta \mathrm{p}_{\mathrm{i}, \mathrm{E}}$ - drop pressure in working chamber of motor supplied with low viscosity fluid (HFA-E emulsion);

- $\omega$ - the angular velocity of the motor shaft;

- $\mathrm{k}_{\mathrm{c}}$ - the coefficient depends on the compressibility module of oil $\mathrm{K}_{\mathrm{O}}$ and emulsion $\mathrm{K}_{\mathrm{E}}$, expressed by the equation:

$$
k_{C}=\frac{K_{O}}{K_{E}}
$$

- $\mathrm{Q}_{1, \mathrm{O}}$ - the component of volumetric losses with laminar nature in a motor supplied with oil:

$$
Q_{l, O}=\frac{C_{o l, O}}{\mu_{o}} \cdot \frac{q_{t}}{2 \cdot \pi} \cdot \Delta p_{i, O} \cdot\left(1+B_{h} \cdot \Delta p_{i, O}\right)^{3}
$$

- $\mu_{0}$ - the dynamic viscosity of oil (for atmospheric pressure) in temperature $\mathrm{T}_{1}$ in the inflow port of a motor;

- $\mathrm{Q}_{\mathrm{t}, \mathrm{O}}$ - the component of volumetric losses with turbulent nature in a motor supplied with oil:

$$
Q_{t, O}=C_{o t, O} \cdot \sqrt{\frac{2 \cdot \Delta p_{i, O}}{\rho_{O}}} \cdot \sqrt[3]{\left(\frac{q_{t}}{2 \cdot \pi}\right)^{2}}
$$

$-\rho_{\mathrm{O}}-$ the density of oil;

- $\mathrm{k}_{\mathrm{s}}$ - the coefficient. For not fully developed turbulent flow of emulsion:

$$
k_{S}=0,9 \cdot \frac{\mu_{O}}{\mu_{E}} \cdot \Delta p_{i, O}{ }^{-3 / 7}
$$

but for laminar flow of emulsion:

$$
k_{S}=\frac{\mu_{O}}{\mu_{E}}
$$

- $\mathrm{m}_{\mathrm{E}}$ - the dynamic viscosity of HFA-E emulsion (for atmospheric pressure) in temperature $\mathrm{T}_{1}$ in the inflow port of motor;

- $\mathrm{Q}_{\mathrm{ex}, \mathrm{O}}$ - the external leakages of oil, expressed by the formula;

$$
Q_{e x, O}=\frac{C_{e x, O}}{\mu_{O}} \cdot \frac{q_{t}}{2 \cdot \pi} \cdot p_{2, O}
$$

- $\mathrm{p}_{2, \mathrm{O}}$ - pressure in outflow port in motor supplied with oil;

- $\mathrm{B}_{\mathrm{h}}, \mathrm{k}_{\mathrm{ex}}, \mathrm{C}_{\mathrm{s}, \mathrm{O}}, \mathrm{C}_{\mathrm{s}, \mathrm{E}}, \mathrm{C}_{\mathrm{ex}, \mathrm{E}}, \mathrm{C}_{\mathrm{l}, \mathrm{O}}, \mathrm{C}_{\mathrm{t}, \mathrm{O}}$ - the coefficients.

The pressure drop $\Delta \mathrm{p}_{\mathrm{i}, \mathrm{O}}$ in working chambers of a motor supplied with oil is [21]:

$$
\Delta p_{i, O}=\Delta p-\Delta p_{i c h, O}
$$

but the pressure drop $\Delta \mathrm{p}_{\mathrm{i}, \mathrm{E}}$ in working chambers of a motor supplied with emulsion is described by the equation:

$$
\Delta p_{i, E}=\Delta p-\underbrace{k_{H} \cdot \Delta p_{i c h, O}}_{\Delta p_{i c h, E}}
$$

Where $[1,21]$

- $\Delta \mathrm{p}_{\text {ich,O }}$ - the pressure drop in internal channel of a motor supplied with oil:

$$
\Delta p_{i c h, O}=C_{i c h, O} \cdot \rho_{O} \cdot \omega^{2} \cdot \sqrt[3]{\left(\frac{q_{t}}{2 \cdot \pi}\right)^{2}}
$$

- $\mathrm{C}_{\text {ich,O }}$ - the coefficient

- $\mathrm{k}_{\mathrm{H}}$ - the coefficient described by:

$$
k_{H}=\frac{\rho_{E}}{\rho_{O}} \cdot\left(\frac{Q_{E}}{Q_{O}}\right)^{2}
$$

- $\rho_{\mathrm{E}}-$ the density of emulsion.

The Paszota Z. and Maczyszyn A. $[9,11]$ description of volumetric losses is dependent on the type of machine (pump or motor) and does not show the sources of these losses. The volumetric losses according to Paszota $Z$. and Maczyszyn A. are as follows $[9,11]$ :

a) for a motor with constant displacement:

$$
Q_{l}=k_{9} \cdot Q_{P t} \cdot\left(\frac{\Delta p_{i}}{p_{n}}\right)^{a_{p v}} \cdot\left(\frac{n}{n_{t}}\right)^{a_{n v}} \cdot\left(\frac{v}{v_{n}}\right)^{a_{v v}}
$$

b) for a pump with constant displacement:

$$
Q_{l}=k_{1} \cdot q_{P t} \cdot n_{p} \cdot\left(\frac{\Delta p_{i}}{p_{n}}\right)^{a_{p v}} \cdot\left(\frac{v}{v_{n}}\right)^{a_{v v}}
$$


where:

- $\mathrm{k}_{1}, \mathrm{k}_{9}, \mathrm{a}_{\mathrm{pv}}, \mathrm{a}_{\mathrm{vv}}, \mathrm{a}_{\mathrm{nv}}-$ coefficients;

- $\mathrm{n}_{\mathrm{p}}$ - speed of pump;

- $\mathrm{n}_{\mathrm{t}}, \mathrm{n}$ - theoretical and actual speed of motor;

- $\mathrm{p}_{\mathrm{n}}$ - nominal pressure in hydraulic circuit;

- $\Delta \mathrm{p}_{\mathrm{i}}$ - pressure drop in working chambers of a pump or motor;

- $\mathrm{q}_{\mathrm{pt}}$ - theoretical displacement of pump;

- $\mathrm{Q}_{\mathrm{Pt}}$ - theoretical capacity of pump.

- $v_{n}$ - related kinematic viscosity $\left(v_{n}=35 c S t\right)$.

The inconvenience of these models is that they describe the volumetric losses in general, without specifying the type of gaps and other sources of these losses. In addition, the leakage of a low viscosity liquid (like water or HFA-E emulsion) is described by a different mathematical formula than the leakage of a high-viscosity liquid (like mineral oil or vegetable oil). Therefore, it was advisable to develop a new method to describe the volumetric losses in a satellite motor - a universal method for both high viscosity and low viscosity liquids.

\section{NEW MATHEMATICAL DESCRIPTION OF VOLUMETRIC LOSSES}

Volumetric losses $\mathrm{Q}_{\mathrm{vl}}$ in the hydraulic motor are proposed to be express as (Fig. 7):

$$
Q_{v l}=Q_{L f g}+Q_{C}+\underbrace{\Delta Q_{f c}+\Delta Q_{d c h}+\Delta Q_{b}+\Delta Q_{i d}}_{\Delta Q_{v l}}+Q_{e x}
$$

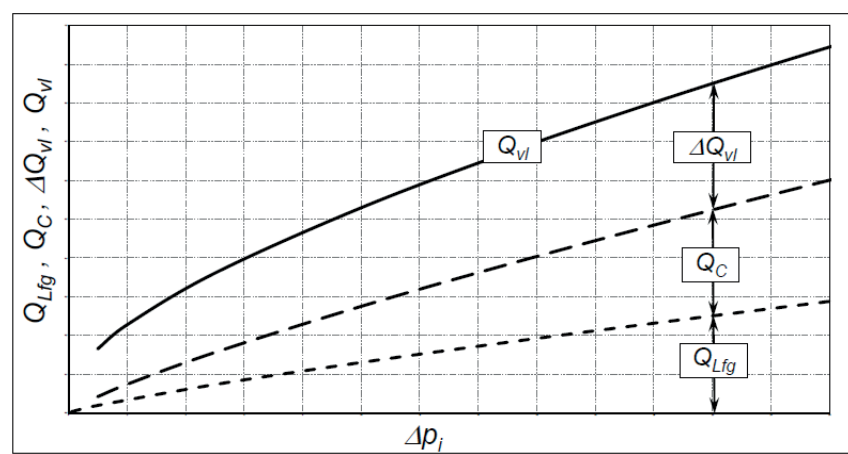

Fig. 7. Characteristic of components of volumetric losses in hydraulic motor

The components $\mathrm{DQ}_{\mathrm{fc}}, \mathrm{DQ}_{\mathrm{dch}}, \mathrm{DQ}_{\mathrm{b}}$ are proportional to both the pressure drop $\mathrm{Dp}$ in the working chambers and the effective engine speed $n$. But, the component $\mathrm{DQ}_{\mathrm{id}}$ is only dependent on $\mathrm{n}$. That is:

$$
\Delta Q_{v l}=\Delta Q_{f c}+\Delta Q_{d c h}+\Delta Q_{b}+\Delta Q_{i d}=\Delta q \cdot n
$$

From the equations (11),(12),(13),(14) and (35) it follows that:

$$
\Delta \mathrm{q}=(\underbrace{\left(C_{f c} \cdot \beta_{l}+C_{d c h}+C_{b}\right)}_{C} \cdot \Delta p_{i}+\frac{C_{i d}}{n^{0,5}}) \cdot m^{2} \cdot H
$$

All components of volumetric losses depend on the drop pressure $\Delta \mathrm{p}_{\mathrm{i}}$ in working chambers. The pressure in the working chambers is difficult to measure. In normal engine operating conditions the pressure is measured at its ports. Thus, it is convenient to use the pressure drop Dp in the motor. The relationship between the pressure drop in the motor $\Delta \mathrm{p}$ and pressure drop $\Delta \mathrm{p}_{\mathrm{i}}$ in its chambers, is as follows:

$$
\Delta p_{i}=\Delta p-\Delta p_{i c h}
$$

Internal channels in motors have a complex geometry. In these channels, there is a turbulent, not fully developed flow. To describe the pressure drop $\Delta \mathrm{p}_{\text {ich }}$ in the internal channels, it is proposed to adopt a simplified relationship as [18]:

$$
\underbrace{\mathrm{C}_{\mathrm{t}} \cdot \rho \cdot \mathrm{Q}^{2}}_{\text {lent flow component }}+\underbrace{\mathrm{C}_{\mathrm{l}} \cdot \mu \cdot \mathrm{Q}}_{\text {laminar flow component }}
$$

where $\mathrm{C}_{1}$ and $\mathrm{C}_{t}$ are coefficients depend on geometrical dimensions of internal channels.

\section{RESULTS OF EXPERIMENTAL RESEARCH AND SIMULATION}

The motor SM-0,75/25 was tested using:

- the Total Azolla $46\left(v=40 \mathrm{cSt}, \rho=873 \mathrm{~kg} / \mathrm{m}^{3}\right)$ oil;

- pure tap water $\left(v=0,853 \mathrm{cSt}, \rho=996 \mathrm{~kg} / \mathrm{m}^{3}\right)$.

The motor parameters directly measured on the test stand are:

- pressure $\mathrm{p}_{1}$ in the motor inlet port and pressure $\mathrm{p}_{2}$ in the motor outflow port;

- torque $\mathrm{M}$ on the motor shaft;

- motor absorbency Q (the flow rate to the motor);

- the rotational speed of the motor shaft $n$.

The flow rate $\mathrm{Q}$ in the motor is:

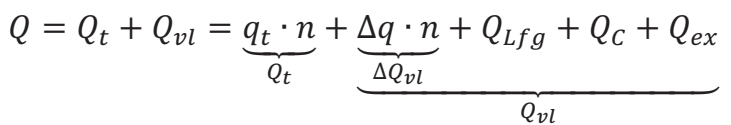

where $\Delta \mathrm{q}$ is the change of displacement coming at one rotation of motor shaft.

The volumetric losses $\mathrm{Q}_{\mathrm{vl}}$ are a function of pressure drop $\Delta \mathrm{p}_{\mathrm{i}}$ in motor working chambers. In this connection it is necessary to designate the pressure drop $\Delta \mathrm{p}_{\text {ich }}$ in the internal channels. The methodology of measuring the $\Delta \mathrm{p}_{\text {ich }}$ is described in [18]. The $\Delta \mathrm{p}_{\text {ich }}$ is described by formula (35) and values of coefficient are given in Table 1 .

The volumetric losses $\mathrm{Q}_{\mathrm{vl}}$ were determined from experimental data according the formula:

$$
Q_{\mathrm{vl}}=Q-\mathrm{q}_{t} \cdot n
$$

The characteristics of volumetric losses $\mathrm{Q}_{\mathrm{vl}}$ in the motor can be presented as a function of $\Delta \mathrm{p}_{\mathrm{i}}$ when:

a) the flow rate $\mathrm{Q}$ is constant $(\mathrm{Q}$ is the parameter independent of the motor) - Fig. 8. Then when load $\mathrm{M}$ of the motor 
(thereby $\Delta \mathrm{p}_{\mathrm{i}}$ ) increases, the speed $\mathrm{n}$ of motor shaft decreases;

a) the speed $\mathrm{n}$ of motor shaft is constant - Fig. 9 and Fig. 10. Then when load $\mathrm{M}$ of the motor (thereby $\Delta \mathrm{p}_{\mathrm{i}}$ ) increases, the absorbency $\mathrm{Q}$ of motor increases also.

In Fig. 9 and Fig. 10 the characteristics of $Q_{\mathrm{Lfg}}+\mathrm{Q}_{\mathrm{C}}$ are shown obtained experimentally and as a result of the calculation accordance with the model (1) and (5). The methodology for determining the components $\mathrm{Q}_{\mathrm{Lfg}}$ and $\mathrm{Q}_{\mathrm{C}}$ are described in $[14,17]$.

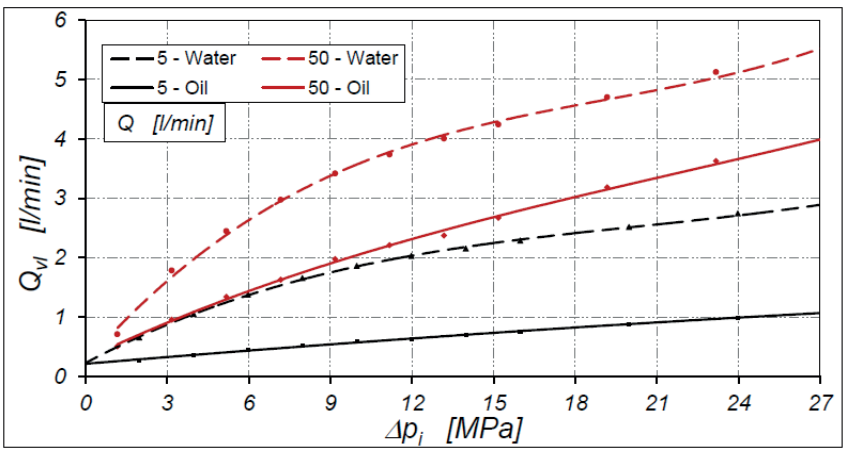

Fig. 8. Characteristics of $Q_{v l}=f\left(D p_{i}\right)$ for $Q=$ const. in motor supplied with oil and water

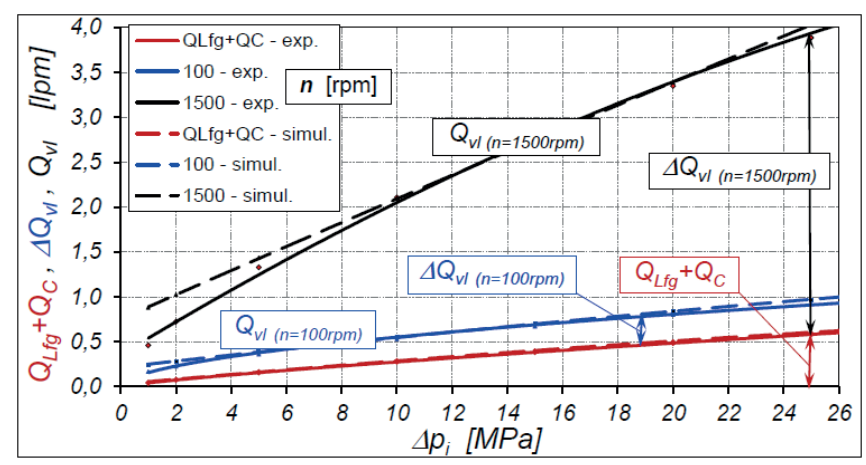

Fig. 9. Characteristics of $Q_{v l}=f\left(D p_{i}\right)$ for $n=$ const. in motor supplied with oil

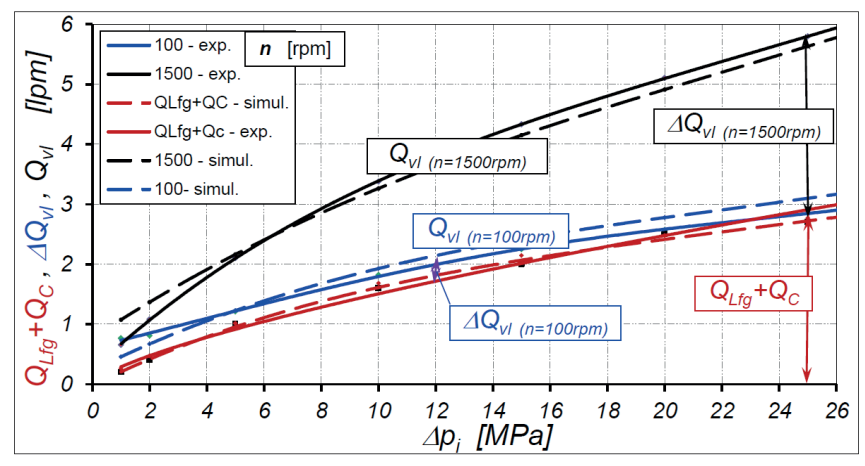

Fig. 10. Characteristics of $Q_{v l}=f\left(D p_{i}\right)$ for $n=$ const. in motor supplied with water

From the formula (36) it follows that (after the adoption of $\mathrm{Q}_{\mathrm{ex}}=0$ ):

$$
\Delta q=\frac{Q-Q_{L f g}-Q_{C}}{n}-q_{t}
$$

In Fig. 9 and Fig. 10 are shown the characteristics of $\Delta \mathrm{Q}_{\mathrm{vl}}$ obtained experimentally. But experimentally obtained characteristics of $\Delta \mathrm{q}$ as a function of $\Delta \mathrm{p}_{\mathrm{i}}$ are shown in Fig. 11 and Fig. 12.

The values of coefficients $C$ and $C_{i d}$ of model (33) can be calculated from the equation of the trend line of experimental characteristics of $\Delta \mathrm{q}=\mathrm{f}\left(\Delta \mathrm{p}_{\mathrm{i}}\right)$. These values are given in Table 1 . Characteristics of $\Delta \mathrm{q}$, calculated according to formula (33), are plotted in Fig. 11 and Fig. 12.

Whereas the volumetric losses, calculated according to equations (32) are shown in Fig. 9 and Fig. 10 (the dotted line).

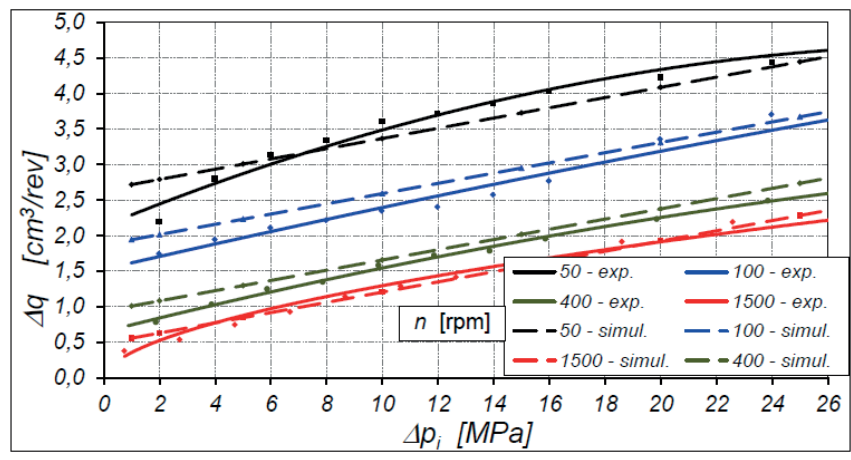

Fig. 11. Characteristics of $\Delta q=f(\Delta p)$ in motor supplied with oil

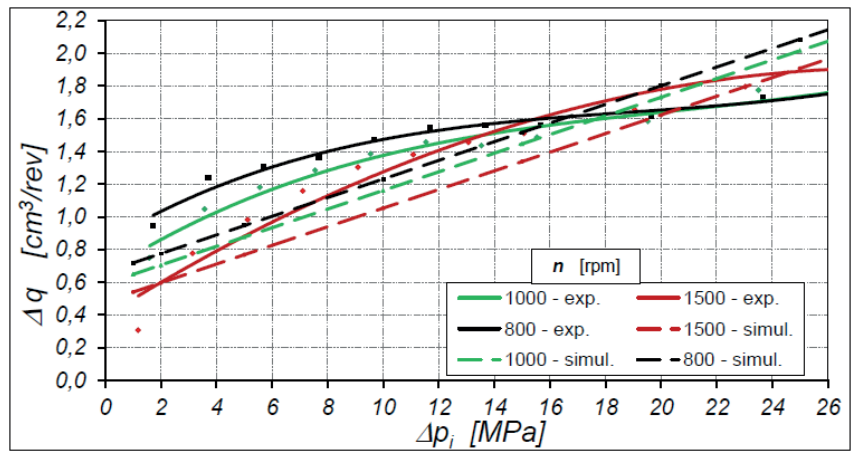

Fig. 12. Characteristics of $\Delta q=f\left(\Delta p_{i}\right)$ in motor supplied with water

Table 1. Values of coefficients in volumetric losses model for motor SM-0,75/25 $[14,17]$

\begin{tabular}{|c|c|c|c|c|c|c|c|}
\hline & $\mathrm{A}_{1}$ & $\overline{\mathrm{A}_{2}}$. & C & $\overline{C_{\mathrm{t}}}$ & $\mathrm{C}_{1}$ & $\overline{C_{\text {id }} .}$ & $\overline{C_{1}}$ \\
\hline & {$[-]$} & {$[-]$} & $\left\lfloor\frac{1}{\mathrm{MPa} \cdot \mathrm{obr}}\right\rfloor$ & {$[-]$} & {$[-]$} & $\left\lfloor\frac{1}{(\mathrm{obr} \cdot \min )^{0,5}} \mid\right.$ & [-] \\
\hline $\begin{array}{l}\text { Oil } \\
\text { Water }\end{array}$ & 0,145 & 0,17 & $\frac{5,12 \cdot 10^{-3}}{4,05 \cdot 10^{-3}}$ & $\begin{array}{r}5,04 \cdot 10^{-6} \\
135 \cdot 10^{-6}\end{array}$ & $\begin{array}{l}9,71 \cdot 10^{-4} \\
174 \cdot 10^{-2}\end{array}$ & 1,33 & $\begin{array}{c}0,077 \\
-125\end{array}$ \\
\hline & $\mathrm{C}_{2}$ & $\mathrm{C}_{3} \ldots$ & $\mathrm{D}_{\mathrm{C}}$ & $\ldots$ & $\mathrm{K}$ & $\gamma$ & $\ldots \beta \ldots$ \\
\hline & {$[-]$} & {$[-]$} & $\left\lfloor\frac{\mathrm{um}}{\mathrm{MPa} \cdot \mathrm{mm}}\right\rfloor$ & $\left|\frac{1}{\mathrm{MPa}}\right|$ & $\left\lfloor\frac{\mathrm{m}}{\mathrm{mPas}}\right\rfloor$ & [-] & [-] \\
\hline Oil & 1,26 & 0,684 & \multirow{2}{*}{$6,4 \cdot 10^{-3}$} & \multirow{2}{*}{$-0,131$} & 1,141 & 0,76 & 0.996 \\
\hline Water & 1,05 & 0,183 & & & 1,0 & 0,55 & 0,655 \\
\hline
\end{tabular}

\section{DISCUSSION}

The test results have shown that the volumetric losses in the motor supplied with water are at most several time greater than the volumetric losses in the motor supplied with oil. The greatest differences was observed for motor supplied 
with a small stream of liquid. Furthermore, for $\mathrm{Q}=$ const., the ratio of $\frac{Q_{v l}-w}{Q_{v l}}$ is variable (Fig. 13). The value of $\Delta p_{i}$, for which the ${ }^{Q_{v l}-0}$ ratio of reaches the maximum, depends on the $\mathrm{Q}$. The smallest value of $\Delta \mathrm{p}_{\mathrm{i}}$ is observed for the smallest values of $Q$. An impact on this phenomenon has:

- change of the nature of the flow (with the increase of $\Delta \mathrm{p}_{\mathrm{i}}$ ) of water and oil in the clearances in the motor working mechanism;

- change of $\Delta \mathrm{q}$ under the influence of $\Delta \mathrm{p}_{\mathrm{i}}$;

- change of engine speed $n$.

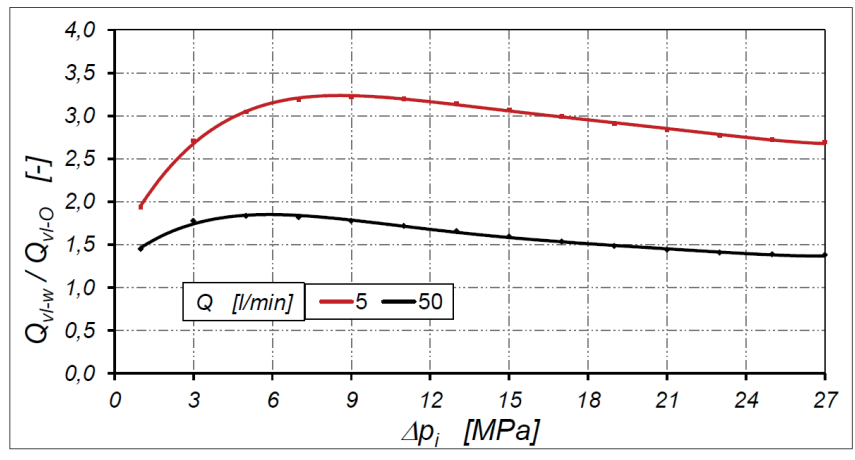

Fig. 13. Characteristics of for motor supplied with oil and water

The mathematical model of volumetric losses has been developed based on the analysis of sources of these losses. It has been shown that on the basis of experimental results, it is possible to calculate the coefficients of the model. Based on the proposed mathematical model, characteristics of volumetric losses were plotted and compared with the results of the experiment. It has been found that the simulation results differ from the results of the experiment:

a) for high speed ( $\mathrm{n}=1500 \mathrm{rpm})$ :

- for $\Delta \mathrm{p}_{\mathrm{i}}=2 \mathrm{MPa}$ - about $35 \%$ both for oil and water;

- for $\Delta \mathrm{p}_{\mathrm{i}}=25 \mathrm{MPa}-$ about $4 \%$ both for oil and water;

b) for low speed $(\mathrm{n}=100 \mathrm{rpm})$ :

- for $\Delta \mathrm{p}_{\mathrm{i}}=2 \mathrm{MPa}$ - about $20 \%$ for oil and $35 \%$ for water;

- for $\Delta \mathrm{p}_{\mathrm{i}}=25 \mathrm{MPa}-7 \%$ both for oil and water.

It turns out that the greatest impact on accuracy of calculation of the volumetric losses has the accuracy of calculation of the change of motor displacement $\Delta \mathrm{q}$. The Dq calculated according to (33) gives the biggest mistake in the range of small values of $\Delta \mathrm{p}_{\mathrm{i}}$ (the biggest differences are observed for $\Delta \mathrm{p}_{\mathrm{i}}<6 \mathrm{MPa}-$ Fig. 11 and Fig. 12). The smaller error in the lower range of $\Delta \mathrm{p}_{\mathrm{i}}$ is obtained if $\Delta \mathrm{q}$ is described by the following empirical formula (this model does not reflect the physical phenomenon):

$$
\Delta q=\frac{C_{1}}{\sqrt{n}} \cdot \Delta p^{\frac{C_{2}}{\sqrt{n}}}
$$

where the values of constants are:

- for water: $\mathrm{C}_{1}=10,6 \mathrm{i}_{2}=0,1$;

- for oil: $\mathrm{C}_{1}=11,7 \mathrm{i}_{2}=0,1$.

Then for low pressure drop $\left(\Delta \mathrm{p}_{\mathrm{i}}=2 \mathrm{MPa}\right)$ the calculations differ from the results of the experiment: a) for high speed ( $n=1500 \mathrm{rpm})-10 \%$ for oil and $25 \%$ for water;

b) for low speed ( $\mathrm{n}=100 \mathrm{rpm})-8 \%$ for oil and $20 \%$ for water. However, the results of calculations of $\Delta \mathrm{q}$, according to the above model, for high $\Delta \mathrm{p}_{\mathrm{i}}$ are heavily biased. Therefore, it is proposed to describe the $\Delta$ q generally by the formula (33). By way of exception, in order to increase the accuracy of the simulation of volumetric losses in the motor operating at low load, it is permitted to accept model (39).

The effect of volumetric losses in the hydraulic motor is a drop of speed $n_{1}$. The real engine speed $n$ can be calculated from the relationship (36) taking into account the equation (33). Then:

$n=\left(\frac{\left(C_{i d}{ }^{2} \cdot m^{4} \cdot H^{2}+4 \cdot\left(q_{t}+C \cdot \Delta p_{i} \cdot m^{2} \cdot H\right) \cdot\left(Q-Q_{L f g}-Q_{C}\right)\right)^{0,5}-C_{i d} \cdot m^{2} \cdot H}{2 \cdot\left(q_{t}+C \cdot \Delta p_{i} \cdot m^{2} \cdot H\right)}\right)^{2}$

The loss of speed $n_{1}$ may be calculated from the equation:

$$
n_{l}=\frac{Q}{q_{t}}-n
$$

The characteristics of $\mathrm{n}_{\mathrm{l}}=\mathrm{f}\left(\Delta \mathrm{p}_{\mathrm{i}}\right)$ are shown in Fig. 14 and Fig. 15 .

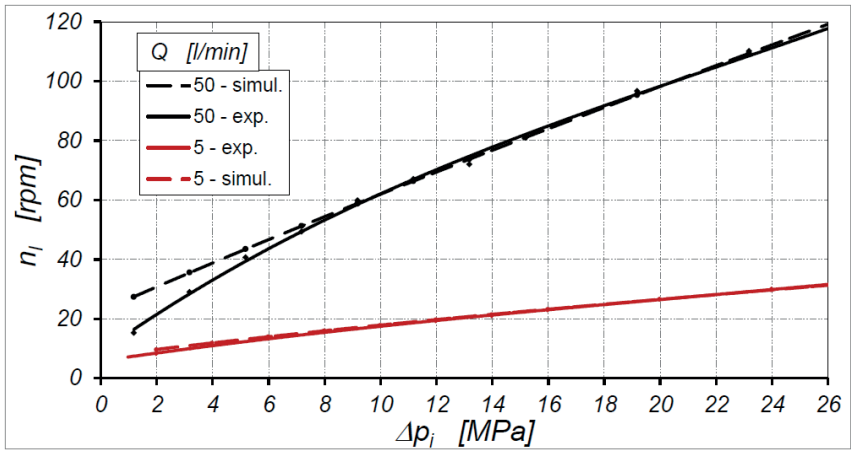

Fig. 14. Characteristics of $n_{l}=f\left(\Delta p_{i}\right)$ - result of experiment and calculation according to formulas (40) and (41). The motor supplied with oil

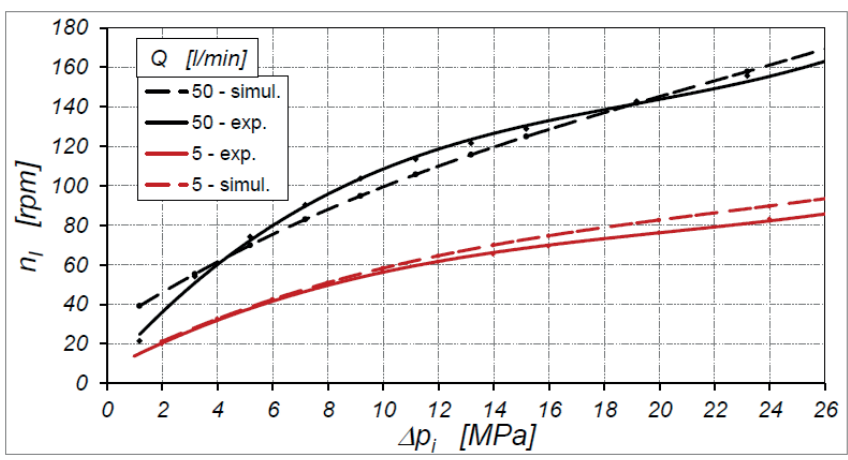

Fig. 15. Characteristics of $n_{l}=f\left(\Delta p_{j}\right)$ - result of experiment and calculation according to formulas (40) and (41). The motor supplied with water

Thus, it is easy to estimate how much the motor speed will be reduced if the motor will be supplied with a low viscosity liquid (like water). In Fig. 16 are shown characteristics of speed ratio of the motor supplied with water $\left(n_{w}\right)$ and the motor supplied with oil $\left(\mathrm{n}_{\mathrm{o}}\right)$. 


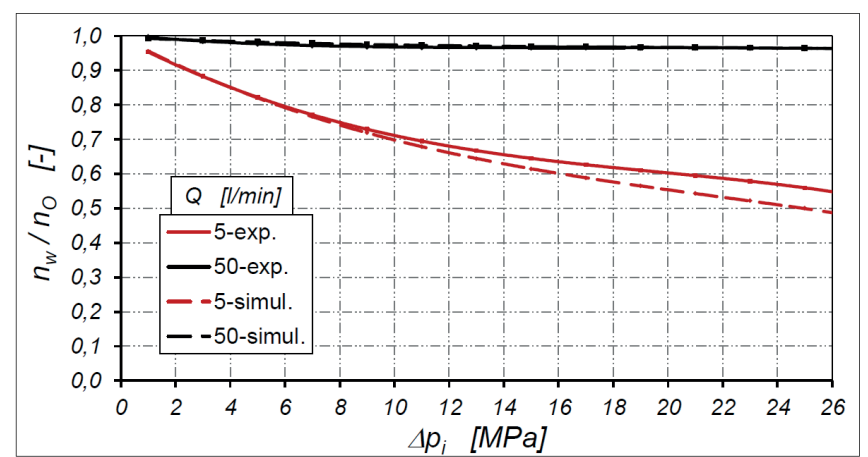

Fig. 16. The ratio of motor speed supplied with water (nw) and supplied with oil (no)

Thus, with a small constant stream of water $(\mathrm{Q}=5 \mathrm{l} / \mathrm{min})$ and at high pressure drop in motor $\left(\Delta \mathrm{p}_{\mathrm{i}}=25 \mathrm{MPa}\right)$ the speed of motor is reduced even by half (in comparison to speed of motor supplied with oil)!

In conclusion, the mathematical model of volumetric losses, presented in this paper, describes quite accurately these loses in the motor supplied with both a mineral oil or water. Therefore, the volumetric losses in the motor supplied with various liquids can be assessed by comparison of the model coefficients.

The mathematical model presented in this article, is a component of a model of overall efficiency of the hydraulic motor. This model is also suitable to describe volumetric losses in a satellite pump.

\section{ACKNOWLEDGMENT}

This article was developed in the framework of the project LIDER/35/102/L-2/10/NCBiR/2011, entitled: „New study of hydraulic satellite machines for drives with bioliquids and non-flammable liquids". This project is funded by the National Centre for Research and Development in Poland.

\section{REFERENCES}

1. Balawender A.: Physical and mathematical model of losses in hydraulic motors. Developments in mechanical engineering, Gdansk University of Technology Publishers. Gdansk 2005.

2. Dymarski C., Dymarski P.: Developing Methodology for Model Tests of Floating Platforms in Low-Depth Towing Tank. Archives of Civil and Mechanical Engineering, No 1/2016, DOI: dx.doi.org/10.1016/j.acme.2015.07.003

3. Guzowski A., Sobczyk A.: Reconstruction of hydrostatic drive and control system dedicated for small mobile platform. American Society of Mechanical Engineers, 2014 doi: dx.doi.org/10.1115/FPNI2014-7862.

4. Jasinski R.: Problems of the starting and operating of hydraulic components and systems in low ambient temperature (Part I). Polish Maritime Research, No 4/2008.
5. Jasinski R.: Problems of the starting and operating of hydraulic components and systems in low ambient temperature (Part II). Polish Maritime Research, No 1/2009.

6. Jasinski R.: Problems of the starting and operating of hydraulic components and systems in low ambient temperature. Part III.Methods of determining parameters for correct start-ups of hydraulic components and systems in low ambient temperatures. Polish Maritime Research, No 4/2009.

7. Litwin W., Olszewski A.: Water-Lubricated Sintered Bronze. Journal Bearings - Theoretical and Experimental Research. Tribology Transactions, vol. 57, No 1/2014.

8. Lubinski J., Sliwinski P.: Multi parameter sliding test result evaluation for the selection of material pair for wear resistant components of a hydraulic motor dedicated for use with environmentally friendly working fluids. Solid State Phenomena, No 225/2015.

9. Maczyszyn A.: Energy analysis of rotary positive displacement machines used in hydrostatic transmissions. $\mathrm{PhD}$ thesis. Gdansk University of Technology, 2014.

10. Osinski P., Deptula A., Partyka M.: Discrete optimization of a gear pump after tooth root undercutting by means of multi-valued logic trees. Archives of Civil and Mechanical Engineering, No 4/2013, DOI: 10.1016/j.acme.2013.05.001.

11. Paszota Z.: Energy losses in hydrostatic drive. LABERT Academic Publishing, 2016.

12. Patrosz P.: Deformation in the axial clearance compensation node in the satellite pump unit. Hydraulics and Pneumatics 1/2014, Poland.

13. Pobedza J., Sobczyk A.: Properties of high pressure water hydraulic components with modern coatings. Advanced Materials Research. Trans Tech Publications Ltd, 849/2014. doi: 10.4028/www.scientific.net/AMR.849.100.

14. Sliwinski P.: Satellite displacement machines. Basis of design and analysis of power loss. Gdansk University of Technology Publishers, 2016.

15. Sliwinski P.: The basics of design and experimental tests of the commutation unit of a hydraulic satellite motor. Archives of Civil and Mechanical Engineering, No 16/2016, DOI: 10.1016/j.acme.2016.04.003.

16. Sliwinski P. Satellite pump and motor. Machines Technologies Materials 9/2014.

17. Sliwinski P.: The flow of liquid in flat gaps of satellite motors working mechanism. Polish Maritime Research, No 2/2014. 
18. Sliwinski P.: Pressure losses and power balance in the unloaded satellite pump. Hydraulika a Pneumatika, No $1-2 / 2013$

19. Sliwinski P.: New satellite pumps. Key Engineering Materials, No 490/2012.

20. Śliwiński, P.: Influence of oil and emulsion HFA-E on flow characteristics in gaps of hydraulics satellite motors (in Polish). Hydraulika i Pneumatyka, No 5/2007.

21. Sliwinski, P.: Comparison of phenomena in hydraulic satellite motors supplied with oil-in-water emulsion and oil. PhD thesis. Faculty of Mechanical Engineering, Gdansk University of Technology, 2006.

22. Urbanczyk J.: Research of hydraulic motors for needs of small mechanization in the mining industry. PhD thesis. AGH University of Science and Technology, 1999.

23. Walczak P., Sobczyk A.: Simulation of water hydraulic control system of francis turbine. American Society of Mechanical Engineers, 2014. doi: dx.doi.org/10.1115/ FPNI2014-7814

24. Zloto T., Nagorka A.: An efficient FEM for pressure analysis of oil film in a piston pump. Applied Mathematics and Mechanics, vol.30, No 1/2009.

\section{CONTACT WITH THE AUTHORS}

\section{Pawel Sliwinski}

e-mail: pawel.sliwinski@pg.gda.pl Gdansk University of Technology, Faculty of Mechanical Engineering

\section{Poland}

